\title{
Analysis of Supply Chain Financing Mode: A Case Study Hua Tang ${ }^{1, a}$, Yijun Meng ${ }^{1, b}$ \\ ${ }^{1}$ School of management, Beijing Normal University, Zhuhai, Guangdong, China a446136353@qq.com, b178070763@qq.com
}

Key words: small and medium sized enterprises; financing difficulties; supply chain finance

\begin{abstract}
For the consideration of the loan risk, most of the commercial banks will not directly lend to SMES. A supply chain on the $80 \%$ of the enterprises are small and medium-sized enterprises, small and medium-sized enterprises can find the stakeholders in the downstream, the special supply chain financing mechanism and jointly create a bear the risk, using this mode of financing can effectively solve the financing problems. This paper focuses on the analysis of supply chain financing of enterprise $\mathrm{Y}$ applicability and implementation of supply chain financing mode, through the comparison of the enterprise supply chain financing and profitability, confirmed the mode of supply chain financing is an effective way to alleviate the financing problems of Y company.
\end{abstract}

\section{中小企业供应链融资模式研究—— - $A$ 企业为例 \\ 唐华 $1, \mathrm{a}$, 孟怡君 ${ }^{1, b}$ \\ 1北京师范大学珠海分校管理学院, 珠海, 广东, 中国 a446136353@qq.com, b178070763@qq.com}

关键词：中小企业；融资难；供应链融资

中文摘要.出于对贷款风险的考虑, 商业银行大多不会直接给予中小企业贷款。而一条供应链 上 $80 \%$ 的企业都是中小企业, 中小企业可在上下游中寻找利益相干者, 并与它们共同创建一 种承当风险的特殊机制——供应链融资, 运用这种融资方式可以有效解决融资难题。本文重 点分析了供应链融资对 $\mathrm{Y}$ 企业的适用性与其供应链融资实施模式, 通过比较该企业实施供应 链融资前后的获利能力，证实了供应链融资模式是缓解Y企业融资问题的有效途径。

\section{1. 引言}

根据有关数据显示，我国中小企业占注册企业总量的 $99 \% ，$ GDP贡献率达到60\%，为城 镇居民提供了 $75 \%$ 以上的就业岗位, 已经成为国民经济发展的主力军。对于中小型的企业来 说, 可在上下游中寻找利益相干者, 与这些企业进行进一步的合作, 从而运用供应链融资模 式解决融资问题。通过这类方法可以使中小企业的融资困难得以解决，还能令银行和企业的 联系更加密切, 达成互利共赢的状态。更能加强整条供应链上的企业合作, 使得供应链上各 个企业的交易和资金流动形成一种协同作用，从而使整个供应链上的企业飞速发展。

\section{2. 文献综述}

供应链融资在国内外研究较为广泛, 研究方向涉及了对于概念的研究和对于实战的研究, 从企业的方面来看, 一般都称之为供应链融资; 从银行方面来看, 一般称之为供应链金融。 
本文从供应链融资的相关概念以及供应链融资的运作模式两个方面来对前人的研究进行归纳 和梳理:

\section{1 国外文献综述}

国外学者对供应链融资的研究有着悠久的历史, 对于这方面的科研成果丰富。供应链融 资定义方面有Pffaf(2004)认为订单周期管理,包括涉及订单、记账、支付过程和IT系统的活动, 是供应链金融的一个重要方面; 另一类对供应链金融的定义, 比较强调生态圈建立对财务和 资金的优化Michael Lamoureux(2008),他认为优化资金的可获性、降低企业生产销售成本的过 程就是供应链融资。

供应链融资模式方面,Mickael Comelli(2008)表示在面对中小企业财务现金流困境时,可以 把融资过程和生产经营链接起来,运用企业存货作为质押物来融资, 以此来减轻企业的现金流 压力，从而使现金和存货达到一种平衡状态。

\section{2国内研究综述}

供应链概念方面：毕家新(2010)对供应链融资项目的孕育前提、源头、以及理论体系进 行了剖析, 从而发表了供应链融资的理论基础就是结构性融资的观点; 庄晋财（2011）等人 则从物流公司角度出发, 对中小企业供应链融资进行了探讨, 将供应链融资分为两大类：一 是以核心企业为主导的产品供应链融资，二是以物流为主导的物流供应链融资。

供应链模式方面: 李善良（2012）、窦亚序(2013)等主要分析供应链金融常见的运作模式 和各个中小企业怎样从自身特点出发, 设计出顺应自身发展的供应链融资模式,从而达到实现 金融资本和实体经济的和谐共进的局面; 徐欣(2012)研究了由两种不同主体提供的供应链融 资模式:一是物流公司通过产业资本的主干地位进行融资, 二是商业银行在经济资本的主干地 位来进行的融资。

\section{3. 供应链融资相关概念}

\section{1供应链概念}

供应链的观念是由波特所发表的价值链观点而得出的。我国的《物流术语》认为，供应 链是在转换过程中, 将产品或服务从多方面、全方位的提供给用户的上游和下游企业, 从而 形成的网状结构。供应链从最初的供方开始, 不断通过 “供”、“需” 两种关系来回转换, 形成 首尾相连的长链, 将服务连接起来, 并通过物流、信息与资金的相互关联, 进行同步发展。 供应链的网链结构如图1所示:

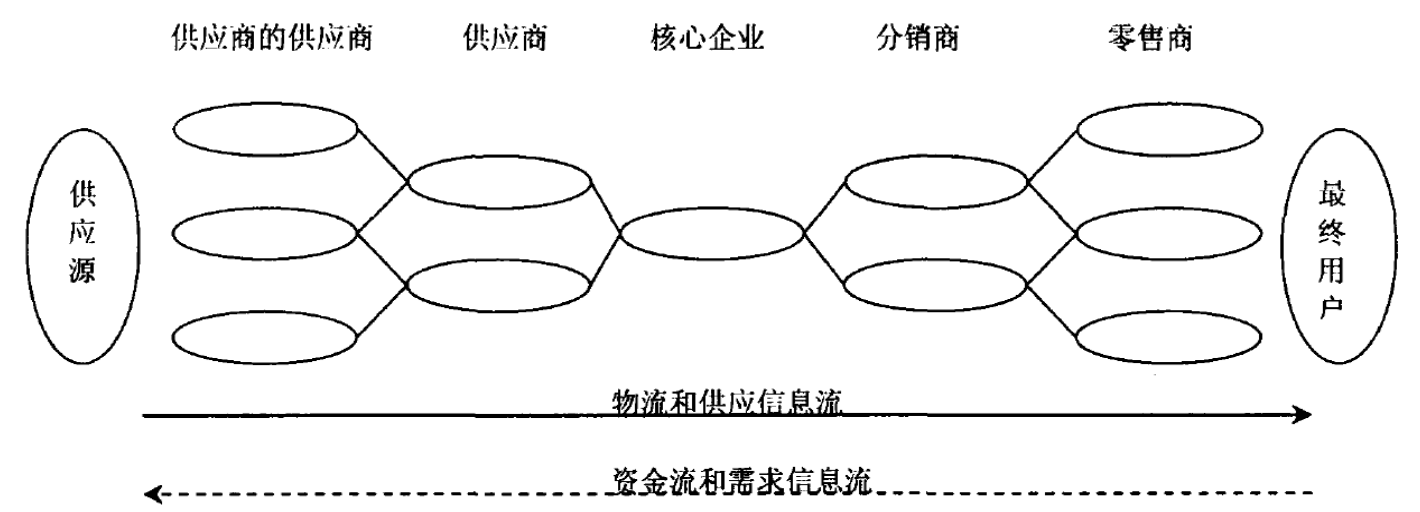

图1. 供应链网链结构 


\section{2供应链融资原理}

供应链融资是由金融机构作为纽带，将企业的整个产业链连接成一个整体，依据该产业 链上的各个企业间的联系, 对产业链上的企业提供关于融资方面的服务。具体而言, 供应链 融资要以中枢企业为基础, 向中枢企业进行上下游方向的拓展, 把发展前景好的中小企业规 入供应链融资业务中。一方面可以将中枢企业信用进行全方位的延伸, 为上下游信用力不高 的中小企业提供信誉保障, 为其继续发展提供融资条件; 另一方面, 供应链融资为整个供应 链上的企业发展创建了广阔的平台, 以便于企业间的长期共赢的合作, 为供应链上的企业部 门的长远发展提供了帮助。

\section{Y企业供应链融资案例}

\subsection{Y 企业背景及融资现状}

Y企业成立时间为1995年, 经营地址位于广东省某二线城市，在职员工 245 人。Y企业是 集研发、生产、销售、技术服务于一体的燃气电子零件供应商。现Y企业决定自主研发适应 高温光电磁阀, 争取开拓新的应用市场, 因此, 该Y企业日前急需进行大量的融资来支持下 一步战略发展。

Y企业在 2015 年仅向银行以市场利率贷款 180 万元，这对于Y企业生产所需的资金来说， 金额远远不能与Y企业的资产和销售收入相匹配，而且这种小额贷款的状况可能还会保持一 段时间不会改变，所以通过传统方式向银行贷款不能成为Y企业的首选，而Y企业为了能够融 到资金扩大生产，必须采用其他的方式。此时Y企业的融资与经营流程见图2所示:

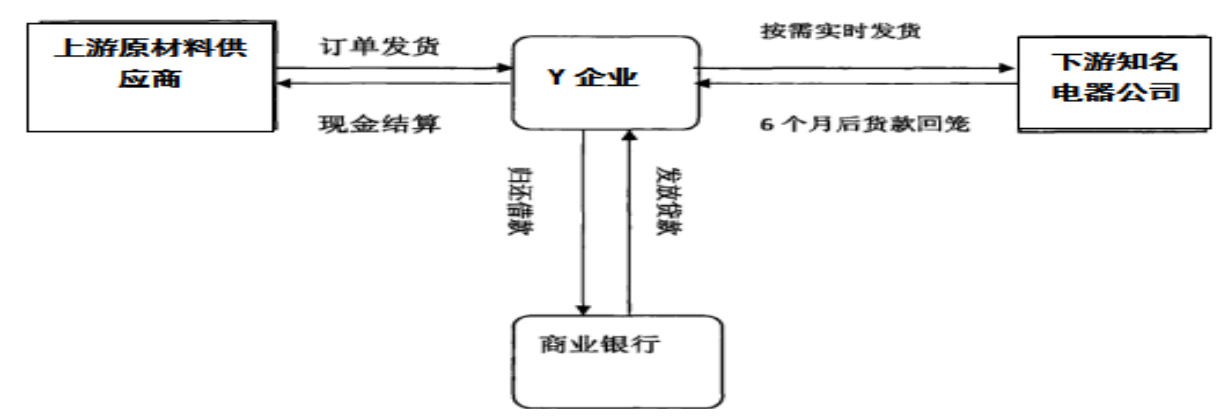

图2. Y企业融资经营流程

\section{2供应链融资业务的介入分析}

供应链融资的关键就是在于在整个供应链之中存在一个拥有银行信任的有实力的核心企 业。根据Y公司各类信息, 分析产业链上下游的交易情况查看是否有实施供应链融资的可能性。 4.2.1企业上游供货渠道分析

Y 企业上游供货企业主要有：博罗县信隆电工材料有限公司、湛江市天隆机电有限公司 等见表 $1, \mathrm{Y}$ 企业与上游客户结算周期一般为3-6个月, 交易结算方式多为转账, 少部分银承。 由于上游企业并没有过多的选择，Y企业在采购上并没有太强的议价能力，所以Y企业采用了 比较价格选择合适价格的企业进行采购, 这就使得Y企业在铝阀等原材料上没有稳定的供应 商, 而不同生产商提供的原材料质量不同，这就使得Y企业在生产时控制生产质量上难度大， 不利于企业的生产发展。 
表1. Y企业主要上游供货商

\begin{tabular}{|c|c|c|c|c|c|c|}
\hline 客户名称 & $\begin{array}{c}\text { 合作时间 } \\
\text { (年) }\end{array}$ & 采购品种 & $\begin{array}{c}\text { 去年采购量 (万 } \\
\text { 元) }\end{array}$ & $\begin{array}{c}\text { 预计本年采 } \\
\text { 购金额 (万 } \\
\text { 元) }\end{array}$ & 结算方式 & 㻌销账期 \\
\hline $\begin{array}{c}\text { 博罗县信隆电工材 } \\
\text { 料有限公司 }\end{array}$ & 10 & 漆包线 & 931 & 1100 & 电汇 & $60-120$ 天 \\
\hline $\begin{array}{c}\text { 湛江市天隆机电有 } \\
\text { 限公司 }\end{array}$ & 10 & 铝㑘体 & 865 & 1000 & $\begin{array}{c}\text { 电汇、银行 } \\
\text { 承兑汇票 }\end{array}$ & $90-180$ 天 \\
\hline $\begin{array}{c}\text { 廉江市翌普电气有 } \\
\text { 限公司 }\end{array}$ & 7 & 冲压、电胶 & 811 & 800 & 电汇 & $60-120$ 天 \\
\hline $\begin{array}{c}\text { 湛江市恒益工贸有 } \\
\text { 限公司 }\end{array}$ & 18 & 铝伐体 & 451 & 500 & 电汇 & $120-180$ 天 \\
\hline 其他 & 其他 & 3316 & 3300 & & \\
\hline 合计 & & 6374 & 6700 & & \\
\hline
\end{tabular}

4.2.2企业下游供货渠道分析

$\mathrm{Y}$ 企业下游销售渠道主要2种: 一方面在国内布局销售网络, 来为国内的下游企业提供配 套产品供应; 另一方面远销海外, 出口东南亚、台湾燃气用具及电子配件货物, Y公司售终端 分散全国各地，其余销售端具体见表 2 。

\begin{tabular}{|c|c|c|c|c|c|c|}
\hline 客户名称 & $\begin{array}{c}\text { 合作 } \\
\text { 时间 }\end{array}$ & 销售产品 & $\begin{array}{c}\text { 2015年销售 } \\
\text { 量 (万元) }\end{array}$ & $\begin{array}{c}\text { 2016年销售金额 } \\
\text { (万元) }\end{array}$ & 结算方式 & 㻌销账期 \\
\hline $\begin{array}{c}\text { 青岛海达瑞采购服 } \\
\text { 务有限公司 }\end{array}$ & 9 & 比例阀 & 2691 & 4000 & $\begin{array}{c}\text { 电汇、承兑 } \\
\text { 汇票 }\end{array}$ & 6-9个月 \\
\hline $\begin{array}{c}\text { 樱花卫厨 (中国) 股 } \\
\text { 份有限公司 }\end{array}$ & 17 & 比例阀 & 1225 & 1500 & $\begin{array}{c}\text { 电汇、承兑 } \\
\text { 汇票 }\end{array}$ & 6-9个月 \\
\hline $\begin{array}{c}\text { 台湾樱花股份有限 } \\
\text { 公司 }\end{array}$ & 18 & $\begin{array}{c}\text { 比例阀、 } \\
\text { 水阀 }\end{array}$ & 818 & 700 & $\begin{array}{c}\text { 电汇、承兑 } \\
\text { 汇票 }\end{array}$ & 5-7个月 \\
\hline $\begin{array}{c}\text { 广东诺科冷暖设备 } \\
\text { 有限公司 }\end{array}$ & 15 & $\begin{array}{c}\text { 比例阀 } \\
\text { 承兑汇票 }\end{array}$ & 6-9个月 \\
\hline 其他 & 603 & 1000 & & \\
\hline 合计 & $\begin{array}{c}\text { 比例阀、 } \\
\text { 水阀等 }\end{array}$ & 1996 & 8100 & & \\
\hline
\end{tabular}

综上可知, $Y$ 企业尽管本身从银行获得贷款的能力不强, 限制了其进一步发展, 但是在 $Y$ 企业所处的供应链中, Y企业的下游企业都拥有较强的实力, 能够成为可以获取银行信任的核 心企业, 这就使得供应链融资的开展有了基础, 同时, 对于整个供应链的发展来说, 处在中 间的Y企业能够从供应链贷款中获得资金进行扩张发展, 对于上下游企业的发展也是有推动作 用的，所以Y企业应该在自身条件下，根据自身财务情况开展供应链贷款。

\subsection{Y 企业供应链融资方案实施内容}

结合现有企业的应收帐款情况及付款方式, 为Y企业作如下综合供应链融资方案:

一是开展存货质押业务，在有担保企业进行担保的前提下，缴纳 30\%的保证金以办理500 万元的银行承兄汇票额度。由此, 实现银企双方的供应链融资业务合作。需要注意的是银行 需确认 Y 企业与上下游企业购销合同的真实性, 并确保企业已经足额缴纳了保证金。在上述 的必要条件得以确认后, 才可以出具 6 个月期至的 500 万银行承兄汇票, 其中银行承兑汇 票具有可循环性。

二是开展国内保理业务, 这是应收账款融资的一种。针对下游买方客户限为青岛海达瑞采 购服务有限公司、樱花卫厨 (中国) 股份有限公司, 两个强势买家的 6 个月回笼应收帐款, 办 理保理应收帐款质押业务, 并在银行应收账款质押登记系统办理登记, 同时追加该公司股东 及各自配偶个人连带责任保证。对标的为 500 万元的银行承兄汇票所释的 350 万元的购销协议 保理，预付款金额要低于该企业转让的合格应收账款金额的 $80 \%$ 。 
至此，Y 企业的信用敞口由原来的 200 万升级到了当前的 500 万，其业务开展流程图3 如下:

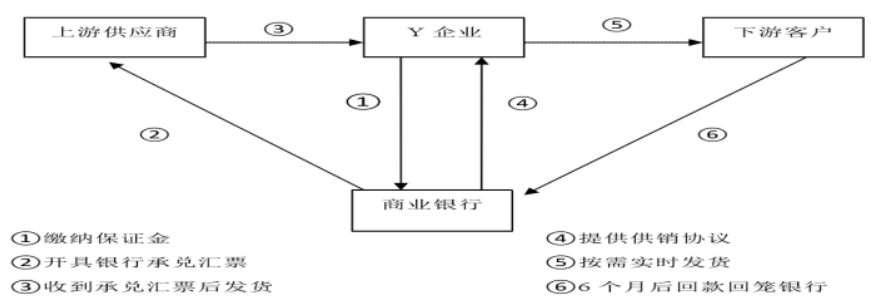

图3. Y企业供应链融资模式流程图

\section{4 实施供应链融资前后获利能力比较}

开展供应链融资是公司经营策略的选择, 这种策略的选择对于Y企业是否提高了其盈利能 力, 需要通过具体的财务指标来反映。在这里选择运用主营业务利润率来作为参考指标, 这 个指标不仅考察企业创造收入的能力, 也考察企业在成本控制方面的能力, 同样数额的收入 创造更多的利润，也就意味着企业的竞争力强，拥有更强的发展潜力。其计算公式如下:

主营业务利润率=销售利润 $\div$ 营业收入 $\times 100 \%$

2016时, Y企业从传统融资模式向供应链融资模式转变, 主营业务利润率从17. 7\%提升到了 $28.6 \%$, 这种盈利能力的提高离不开供应链融资模式带来的帮助, 这种帮助不仅仅是因为Y公 司因为供应链融资多得到了500万的信贷资金，同时也因为供应链融资本身提高了资金的效 率，两者产生的共同作用才是供应链融资模式真正的优势。

从财务角度来看, $\mathrm{Y}$ 企业全年应收账款周转次数为 2 次，销售平均的获利水平为 $15 \%$, 一 年期贷款利率 $6 \%$, 存款利率 $3.5 \%$ 。按原有融资方案企业获得 500 万元流动资金贷款进行计算, 市场利率水平即 1 年期贷款利率上浮 40\%的情况下, 银行办理承兑汇票手续费按 $0.05 \%$ 收 取。

下为 $\mathrm{Y}$ 企业及商业银行的收入对比见表3、4:

表3. 企业传统融资与供应链融资收入对比（万元）

\begin{tabular}{|c|c|c|}
\hline 科目 & 传统方式贷款 & 供应链融资 \\
\hline 企业收入 & 105 & 155 \\
\hline 销售收入 & 1000 & 1500 \\
\hline 销售利润 & 150 & 225 \\
\hline 贷款利息 & 42 & 0 \\
\hline 保理费用 & 0 & 23.5 \\
\hline 承兑汇票费用 & 0 & 10.5 \\
\hline
\end{tabular}

表4. 银行传统融资与供应链融资收入对比（万元）

\begin{tabular}{|c|c|c|}
\hline 科目 & 传统方式贷款 & 供应链融资 \\
\hline 银行收入 & 42 & 42.75 \\
\hline 承兑汇票收入 & 1000 & 10.5 \\
\hline 保理业务收入 & 150 & 23.5 \\
\hline 企业存款沉淀收益 & 42 & 3.5 \\
\hline 承兑汇票保证金收益 & 0 & 5.25 \\
\hline
\end{tabular}

\section{5. 研究结论}

综上可见，能从供应链融资模式中收益的不仅仅只是Y企业。首先，供应链融资模式在一 定程度上缓解了 $\mathrm{Y}$ 企业在生产扩张时遇到的资金压力, 使得Y企业能够扩大规模, 提高盈利能 力。从整个供应链来看, Y企业在开展供应链融资的时候, 必然会先和上下游企业产生紧密合 作, 同时随着这种融资的展开, 这种关系将会越来越紧密, 这种供应链内部的紧密型的提高, 
会使得供应链整体在应对风险时具有更强的抗压能力。最后就是银行本身也会受益, 不仅在 于银行能够可以在控制风险的情况下发放一笔贷款获得盈利, 同时银行和供应链中的企业都 建立的关系, 这在之后可能给银行带来更多业务, 而且银行在对整个供应链的风险把握上也 将更加方便。

\section{致谢}

本文为广东省重大科研项目 (项目号2016GXJK191)的阶段性成果之一。

\section{References}

[1] Xie Shiqing, he bin. Analysis of three typical models of international supply chain finance [J]. economic theory and economic management, 2013 (4)

[2] Yu Jianmei. Supply chain finance to ease the financing difficulties of small and medium enterprises [J]. economy, 2011 (03)

[3]Zhao Yajuan, Yang Xisun, and [10]. Supply chain finance and financing ability of SMEs [J]. regional financial research, 2010 (11)

[4]Arqum Mateen,Dileep More.Applying TOC Thinking Process Tools in Managing Challenges of Supply Chain Finance: A Case Study[J]. Int. J. Services and Operations Management,2013,15(4):389-407.

[5]Viktoria Sadlovska.Supply Chain Finance for Emerging Markets[J]. Supply Chain Brain,2012,16(1):7-28. 